\title{
Determination of Radiation Shielding Properties of Some Polymer and Plastic Materials against Gamma-Rays
}

\author{
O. Gurler and U. Akar TARim* \\ Uludag University, Physics Department, Bursa, Turkey
}

\begin{abstract}
A Monte Carlo code is proposed for determination of mass attenuation coefficients of gamma rays for some polymer and plastic materials. It is based on simulation of interaction processes of gamma rays with the energy of $59.5,80.9,140.5,279,356.5,511,661.6,1173.2,1332.5 \mathrm{keV}$ with matter. The method was tested by comparison of the simulation results with the literature values (ANSI/ANS-6.4.3 and GRIC toolkit). The compatible behaviour of mass attenuation coefficients versus incident photon energy for the investigated energy range approves the use of this code for the extended energy range and several materials. Also, the values of half-value layer were calculated for assessment of shielding effectiveness of these materials.
\end{abstract}

DOI: 10.12693/APhysPolA.130.236

PACS/topics: 02.70.Uu, 25.20.Dc, 25.60.Dz

\section{Introduction}

With the increasing use of gamma radiation in various applications in industry, medicine, agriculture, nuclear reactors and particle accelerators, the exposure for longer duration to these radiations can cause very harmful effects on human health. Therefore, the usage of shielding becomes of a paramount importance for using this radiation without a risk [1]. Various researches concerning the interaction of gamma-rays have been published in literature [1-7] and such studies are still actual.

The mass attenuation coefficient is an important parameter for characterization of the penetration and of interaction of gamma-rays with materials. The probability of interaction of gamma-rays per unit of length of a given absorber characterizes its linear attenuation coefficient. However, linear attenuation coefficient depends on the material physical state and for this reason it is usually substituted by the mass attenuation coefficient, which is the linear attenuation coefficient divided by the density [7].

When a gamma radiation beam reaches some absorber material the attenuation occurs in accordance with the material chemical composition and the photon energy, resulting in reduction of its intensity. The decrease of beam intensity results from the combination of photon absorption and deflection. Therefore, mass attenuation coefficient depends on the absorber nature, as well as on the gamma-ray initial energy [7].

In the present work simulations were performed to determine the mass attenuation coefficients for some polymer and plastic materials. The obtained results were compared with the results in literature, obtained by other methods. Calculations of the half-value layer parameters have been carried out for better evaluation of the shielding effectiveness of these materials.

\footnotetext{
*corresponding author; e-mail: uakar@uludag.edu.tr
}

\section{Materials and methods}

In the present study, mass attenuation coefficients of gamma rays for some polymer and plastic materials have been calculated and the values of half-value layer parameter of these materials have been studied to assess their shielding effectiveness. Elemental compositions and densities of studied materials obtained from the literature are given in Table I.

The mass attenuation coefficients, $\mu / \rho\left(\mathrm{cm}^{2} \mathrm{~g}^{-1}\right)$ were calculated according to Eq. (1), which is based on the Lambert-Beer law:

$$
\frac{\mu}{\rho}=\frac{1}{\rho t} \ln \left(\frac{I_{0}}{I}\right)
$$

where $\rho$ is the density of sample, $I_{0}$ and $I$ are incident and transmitted intensities, respectively, and $t$ is the thickness of the sample. The transmitted intensity of photons was determined by Monte Carlo simulation. Attenuation of a collimated beam of one million gamma-rays was simulated for each of samples using the method detailed in

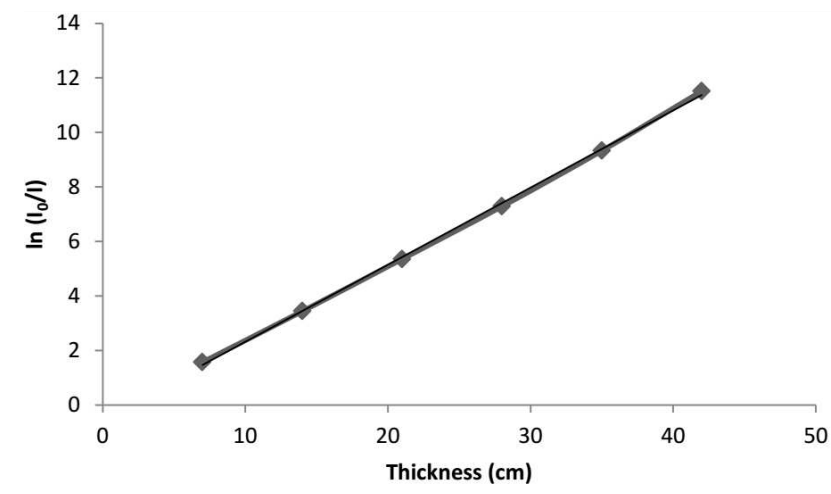

Fig. 1. Plot of $\ln \left(I_{0} / I\right)$ versus attenuator material thickness (for sample 1 (S1), at photon energy of $80.9 \mathrm{keV})$.

our previous studies $[9,10]$. In our algorithm, for each incident photon, the free path length is sampled according to an exponential distribution. Therefore, the cross 
sections of attenuator samples are calculated with the XCOM database, developed by Berger et al. [11]. A fit relation given in Eq. (2), where $x=\ln E$ and $p_{1}, p_{2}, p_{3}$, $p_{4}$ and $p_{5}$ are parameters of photoelectric absorption and incoherent scattering obtained separately for each sample, was obtained for the energy range of 10-2000 keV by using the cross sections for photoelectric absorption and incoherent scattering.

$$
\mu=\exp \left(p_{1}+p_{2} x+p_{3} x^{2}+p_{4} x^{3}+p_{5} x^{4}\right) .
$$

The photons that reach the detector system are counted. In this way, the transmitted intensity $I$ of photons is obtained. By plotting $\ln \left(I_{0} / I\right)$ versus thickness of target, as shown in Fig. 1, the slope is calculated and this value is used in Eq. (1).

Half value-layer (HVL), the thickness of the shielding materials necessary to reduce the intensity of the gammaray to half of the incident value [12], can be calculated using the following relation

$$
\mathrm{HVL}=\frac{0.693}{\mu},
$$

where $\mu$ is the linear attenuation coefficient.

Elemental composition and density values of the investigated samples [8].

\begin{tabular}{c|c|c|c}
\hline \hline $\begin{array}{c}\text { Sample } \\
\text { code }\end{array}$ & Sample & $\begin{array}{c}\text { Density } \\
{\left[\mathrm{g} \mathrm{cm}^{-3}\right]}\end{array}$ & Elemental composition [\% by weight] \\
\hline S1 & Bone-equivalent plastic (B-100) & 1.45 & $\mathrm{H}(6.55), \mathrm{C}(53.7), \mathrm{N}(2.16), \mathrm{O}(3.21), \mathrm{F}(16.75), \mathrm{Ca}(17.66)$ \\
S2 & Polyvinyl chloride (PVC) & 1.41 & $\mathrm{H}(4.84), \mathrm{C}(38.44), \mathrm{Cl}(56.73)$ \\
S3 & Air-equivalent plastic (C-552) & 1.76 & $\mathrm{H}(2.47), \mathrm{C}(50.17), \mathrm{O}(0.46), \mathrm{F}(46.53), \mathrm{Si}(0.40)$ \\
S4 & Radio chromic dye film (nylon base) & 1.08 & $\mathrm{H}(10.20), \mathrm{C}(65.44), \mathrm{N}(9.89), \mathrm{O}(14.47)$ \\
S5 & Polyethylene terephthalate (mylar) & 1.38 & $\mathrm{H}(4.20), \mathrm{C}(62.51), \mathrm{O}(33.31)$ \\
S6 & Polymethyl methacrylate (PMMA) & 1.19 & $\mathrm{H}(8.06), \mathrm{C}(59.99), \mathrm{O}(31.97)$ \\
M1 & Concrete (NBS) & 2.25 & $\mathrm{H}(0.0056), \mathrm{O}(0.4983), \mathrm{Na}(0.0171), \mathrm{Mg}(0.0024), \mathrm{Al}(0.0456)$, \\
M2 & Water & 1.0 & $\mathrm{Si}(0.3158), \mathrm{S}(0.0012), \mathrm{K}(0.0192), \mathrm{Ca}(0.0826)$ \\
& & $\mathrm{H}(0.1119), \mathrm{O}(0.8881)$
\end{tabular}

\section{Results and discussion}

Firstly, the proficiency of the written Monte Carlo code for simulation of the gamma-ray attenuation has been validated. This validation has been made by comparing the simulation results with values from the literature (Table II). Table II shows that simulation results are in accord with the results of other researchers. Based on this accordance, mass attenuation coefficients for the energies, especially those used in experiments, which are not available in the literature, have been calculated and the results are presented in Table III. Data presented in Table III may provide useful knowledge for the experimental researchers, by providing a superior shielding material for a given radioactive source.

Below $100 \mathrm{keV}$, the highest value of mass attenuation coefficient is obtained for PVC. It shows better attenuation than concrete for low energies and this finding is also supported by the results of Mann et al. [8]. For the values above $100 \mathrm{keV}, \mathrm{S} 4$ has a better shielding effectiveness for gamma-rays.

Another way for assessment of shielding effectiveness of the investigated materials is to calculate the half-value layer thicknesses. The variance of HVL of the selected materials with incident photon energy is shown in Fig. 2. It was observed that the HVL values for all of the studied materials increase sharply up to energy of $100 \mathrm{keV}$,
TABLE II

Comparison of Monte Carlo results with literature values for the validation of the written code.

\begin{tabular}{c|c|c|c|c|c|c}
\hline \hline \multirow{2}{*}{$\begin{array}{c}\text { Energy } \\
{[\mathrm{keV}]}\end{array}$} & \multicolumn{3}{|c}{ Mass attenuation coefficient $\left[\mathrm{cm}^{2} \mathrm{~g}^{-1}\right]$} \\
\cline { 2 - 7 } & $\begin{array}{c}\text { ANS } 6.4 .3, \\
1991\end{array}\left[\begin{array}{c}\text { GRIC-toolkit } \\
{[8]}\end{array}\right.$ & \multicolumn{2}{c}{$\begin{array}{c}\text { Monte Carlo } \\
\text { (This study) }\end{array}$} \\
\cline { 2 - 7 } & Water & Concrete & Water & Concrete & Water & Concrete \\
\hline 100 & 0.167 & 0.170 & 0.165 & 0.167 & 0.163 & 0.170 \\
300 & 0.118 & 0.107 & 0.118 & 0.107 & 0.118 & 0.107 \\
500 & 0.097 & 0.087 & 0.097 & 0.087 & 0.096 & 0.086 \\
800 & 0.079 & 0.071 & 0.079 & 0.071 & 0.078 & 0.071 \\
1000 & 0.071 & 0.064 & 0.071 & 0.064 & 0.070 & 0.064
\end{tabular}

similar to results of Singh et al. [12]. From Fig. 2 it is clear that PVC and radio chromic dye film (nylon base) require larger thickness whereas air-equivalent plastic (C-552) requires the lowest thickness for shielding of gamma-rays.

\section{Conclusions}

Two of the gamma-ray interaction parameters, mass attenuation coefficients and half-value layer values have been studied using a Monte Carlo code. The code provides quick calculations of gamma-ray interaction parameters of the sample for the selected energy grid. 
TABLE III

Calculated values of mass attenuation coefficient of investigated materials.

\begin{tabular}{c|c|c|c|c|c|c|c|c}
\hline \hline \multirow{2}{*}{ Energy } & \multicolumn{7}{|c}{ Mass attenuation coefficient $\left[\mathrm{cm}^{2} \mathrm{~g}^{-1}\right]$} \\
\cline { 2 - 9 } & $\mathrm{S} 1$ & $\mathrm{~S} 2$ & $\mathrm{~S} 3$ & $\mathrm{~S} 4$ & $\mathrm{~S} 5$ & $\mathrm{~S} 6$ & Water & $\begin{array}{c}\text { Con- } \\
\text { crete }\end{array}$ \\
\hline 59.5 & 0.257 & 0.295 & 0.166 & 0.176 & 0.176 & 0.174 & 0.186 & 0.294 \\
80.9 & 0.195 & 0.204 & 0.151 & 0.169 & 0.157 & 0.166 & 0.172 & 0.199 \\
140.5 & 0.143 & 0.142 & 0.126 & 0.143 & 0.134 & 0.141 & 0.151 & 0.142 \\
279 & 0.112 & 0.111 & 0.105 & 0.122 & 0.113 & 0.117 & 0.122 & 0.108 \\
356.5 & 0.104 & 0.101 & 0.095 & 0.109 & 0.100 & 0.107 & 0.113 & 0.101 \\
511 & 0.090 & 0.088 & 0.086 & 0.094 & 0.089 & 0.091 & 0.094 & 0.085 \\
661.6 & 0.081 & 0.078 & 0.079 & 0.084 & 0.079 & 0.082 & 0.085 & 0.078 \\
1173.2 & 0.061 & 0.060 & 0.057 & 0.067 & 0.060 & 0.063 & 0.065 & 0.064 \\
1332.5 & 0.058 & 0.055 & 0.054 & 0.061 & 0.058 & 0.059 & 0.062 & 0.055
\end{tabular}

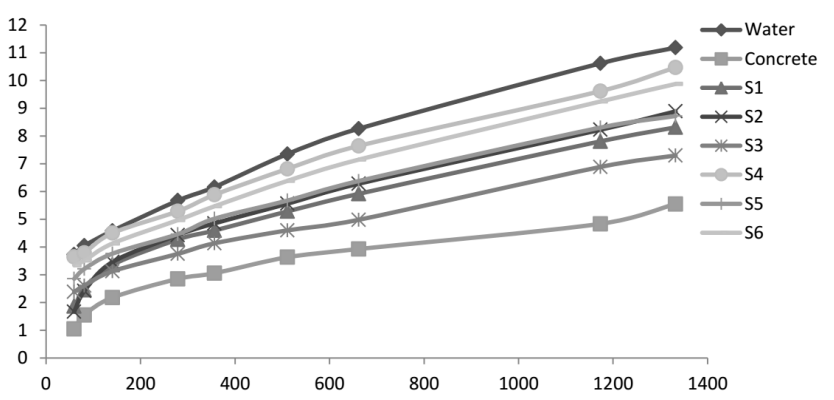

Fig. 2. The variation of half-value layer of the investigated materials with incident photon energy.

Results for investigated parameters are in good agreement with the results from other works in the literature. Finally, a comparison of shielding property of the selected materials leads to conclusion that radio chromic dye film (nylon base) has a better shielding effectiveness than concrete for gamma-rays above $100 \mathrm{keV}$.

\section{Acknowledgments}

We would like to express our sincere gratitude to Prof. Dr. Emin N. Ozmutlu for his fit program and guidance.

\section{References}

[1] Y. Elmahroug, B. Tellili, C. Souga, Ann. Nucl. Ener. 75, 268 (2015).

[2] G.T. Chapman, Nucl. Instr. Methods 52, 101 (1967).

[3] M.T. Teli, L.M. Chaudhari, S.S. Malode, Appl. Radiat. Isotopes 45, 987 (1994).

[4] K. Singh, H. Singh, V. Sharma, R. Nathuram, A. Khanna, R. Kumar, S.S. Bhatti, H.S. Sahota, Nucl. Instr. Methods B 194, 1 (2002).

[5] D. Demir, A. Turşucu, T. Öznülüer, Radiat. Environ. Biophys. 51, 469 (2012).

[6] A.A. Abd El-Latif, K.S. Saeid, H.S. Ragab, A.A. Abdalla, J. Nucl. Radiat. Phys. 8, 19 (2013)

[7] J.C. Costa, J.A.R. Borges, L.F. Pires, R.C.J. Arthur, O.O.S. Bacchi, Ann. Nucl. Ener. 64, 206 (2014).

[8] K.S. Mann, A. Rani, M.S. Heer, Radiat. Phys. Chem. 106, 247 (2015).

[9] O. Gurler, U. Akar Tarim, J. Radioanal. Nucl. Chem. 293, 397 (2012).

[10] U. Akar Tarim, O. Gurler, E.N. Ozmutlu, S. Yalcin Ann. Nucl. Ener. 58, 198 (2013).

[11] M.J. Berger, J.H. Hubbell, S.M. Seltzer, J. Chang, J.S. Coursey, R. Sukumar, D.S. Zucker, K. Olsen, XCOM: photon cross sections database. NIST standard referencedatabase 8 (XGAM), www. nist. gov/ $\mathrm{pml} / \mathrm{data} / \mathrm{xcom} /$ index. cfm/, 2010.

[12] V.P. Singh, N.M. Badiger, A.M. El-Khayatt, Radiat. Eff. Defect S. 169, 547 (2014).

[13] ANSI/ANS-6.4.3, Gamma Ray Attenuation Coeffcient and Buildup Factors for Engineering Materials, American Nuclear Society, La Grange Park, IL 1991. 